American Journal of Pharmaceutical Education 2019; 83 (2) Article 6528.

\title{
RESEARCH
}

\section{A Qualitative Approach to Improving Advanced Pharmacy Practice Experiences in an ACPE International Certified Program}

\author{
Ibrahim Sales, PharmD, ${ }^{\mathrm{a}}$ Mansour Adam Mahmoud, PhD, ${ }^{\mathrm{b}}$ Hisham Aljadhey, PhD, ${ }^{\mathrm{a}}$ \\ Nouf Ibrahim Almeshal, MSc ${ }^{\mathrm{a}}$ \\ ${ }^{a}$ College of Pharmacy, King Saud University, Riyadh, Saudi Arabia \\ ${ }^{\mathrm{b}}$ College of Pharmacy, Taibah University, Al- Madinah Al- Munawarah, Saudi Arabia \\ Submitted May 18, 2017; accepted November 22, 2017; published March 2019.
}

Objective. To explore the opinions and recommendations of university and health care professional experts regarding the Advanced Pharmacy Practice Experiences (APPE) curriculum at the King Saud University College of Pharmacy.

Methods. Forty-eight health care professionals of different backgrounds participated in a roundtable discussion during a 1-day meeting. The discussion revolved around three predefined themes: the doctor of pharmacy (PharmD) program learning outcomes, regulations and responsibilities and APPE activities and syllabi, non-clinical rotations, and assessment. The discussion was transcribed verbatim. Discussion of each theme was summarized and incorporated in the result.

Results. Discussion regarding the PharmD program learning outcomes emphasized clinical outcomes with an additional focus on basic sciences. The regulations and responsibilities table incorporated guidance toward developing student professionalism. APPE activities and syllabi, non-clinical rotations and assessment recommendations encompassed crucial issues such as effective communication among the college, preceptors, and students, scheduled site visits, financial reimbursement for preceptors, student preparatory workshops, and non-clinical rotations.

Conclusion. This roundtable discussion identified many of the concerns and recommendations previously encountered or currently being addressed in many of the previous studies and current accreditation standards. International candidates should consider these recommendations when applying for certification.

Keywords: international certification, APPE, ACPE certification, roundtable, Middle East

\section{INTRODUCTION}

The mission of the Accreditation Council for Pharmacy Education (ACPE) is to ensure and advance excellence in education for the pharmacy profession. ${ }^{1}$ Since its inception in 1932, ACPE has facilitated the adaptation from the baccalaureate degree in pharmacy to the PharmD degree. It further broadened its vision for the profession by initiating the International Services Program (ACPE ISP) in January 2011, which offers international stakeholders the opportunity to receive an International Certification. ${ }^{2}$

The ACPE ISP was founded with the mission to "promote, assure, and advance the quality of pharmacy education internationally to improve patient care through safe and effective medication use." 3 Their vision is to nurture pharmacy graduates with a high quality standard of education to enrich

Corresponding Author: Ibrahim Sales, Department of Clinical Pharmacy, College of Pharmacy, King Saud University, Riyadh, Saudi Arabia. Tel: 803-318-3001. E-mail: isales@ksu.edu.sa the global provision of pharmaceutical services. Although the adaptation of ACPE's International Quality Criteria for Certification of Professional Degree Programs in Pharmacy ("Quality Criteria") is not mandatory, international programs are eligible for consultation, training, and certification through the ACPE ISP program. The Quality Criteria focus on issues such as the development of a mission statement, strategic planning and subsequent evaluation, organization and administration, curriculum recommendations, student services and academic policies, staff resources, and facilities and resources.

Advanced Pharmacy Practice Experiences (APPE) are discussed in both the ACPE Standards for the accreditation of pharmacy schools and colleges in the United States and its territories as well as the ISP Quality Criteria. The standards specifically address the essential elements of APPE requirements, including an emphasis on patient care, diverse populations, interprofessional experiences, APPE duration, and required APPE rotations. ${ }^{4}$ Although 


\section{American Journal of Pharmaceutical Education 2019; 83 (2) Article 6528.}

the ISP Quality Criteria addresses pharmacy practice sites and preceptors, the specifications are not as detailed, and gives international pharmacy schools and colleges the autonomy to establish their own criteria regarding the approval of sites and preceptors. ${ }^{3}$ ACPE provides consultation regarding the specific details and structure of the APPE curriculum.

Interest in the International Certification has intensified following the first International Program Certification granted in 2013 to both the bachelor of pharmacy and doctor of pharmacy programs at the King Saud University College of Pharmacy (KSU-COP) in Riyadh, Saudi Arabia. ${ }^{5}$ Accreditation differs from certification in many aspects. Succinctly, pharmacy colleges or schools seeking accreditation are guided by the Accreditation Standards and Guidelines for the Professional Program in Pharmacy Leading to the Doctor of Pharmacy Degree that ensures their compliance with nationally recognized standards and quality measures. The International Certification indicates that certified programs are amenable to the international standards of pharmacy education and quality measures. ${ }^{5}$ Jagadguru Sri Shivarathreeswara University College of Pharmacy in India, Near East University Faculty of Pharmacy in Northern Cyprus, King Faisal University College of Clinical Pharmacy in Saudi Arabia, and Al Ain University of Science and Technology College of Pharmacy in the United Arab Emirates have all attained certification status with many other programs vying to attain similar recognition. ${ }^{6}$

Pharmacy education in the Middle East is ripe with potential, although there remain many challenges. The first pharmacy college was established at King Saud University in $1959 .^{7}$ From its inception, as with the majority of colleges in this region, the educational standards have been primarily modeled after the American system. ${ }^{8}$ However, although the PharmD degree has been the sole degree offered in pharmacy education in the United States since 1992, the bachelor of pharmacy and the PharmD degree remain options for students in many parts of the Middle East. ${ }^{9}$ Furthermore, although the local pharmacy boards and practitioners make professional distinctions, there still remains a lack of distinction between the bachelors and PharmD degrees among the licensing organizations. ${ }^{10}$

Accreditation and certification remain the most illustrious aspirations of these colleges and distinguish them from their counterparts. These aspirations are enticing not only to programs in the Middle East, but they are also a global ambition. Pharmacy schools seek validation from highly esteemed accrediting bodies to prove that their programs are comparable with international standards. Locally, they strive to maintain societal clout and allure top candidates to their programs. ${ }^{11}$ A lack of qualified preceptors, ineffective new preceptor training and established preceptor development programs, unattractive recruitment incentives, and the absence or minimal availability of joint clinical positions remain the most daunting challenges for pharmacy colleges in the Middle East. ${ }^{9,12,13}$

Since 2008, KSU-COP has been pursuing accreditation from the National Commission for Academic Accreditation and Assessment (NCAAA) in Saudi Arabia, the Canadian Counsel for Accreditation of Pharmacy Programs (CCAPP), and the ACPE ISP. ${ }^{14}$ Many of the requirements overlap, and the breadth of multiple recommendations from various professional regulating bodies, although strenuous, prepared KSU-COP for each subsequent accreditation/certification visit. At the time of the ACPE ISP certification visit, KSU-COP had received accreditation from NCAAA and an extension of provisional status by CCAPP. ${ }^{15}$ Specific benefits acquired via the CCAPP application process included a revision of the curriculum and development of relevant courses, streamlining of the admission process, the dean of the KSU-COP assumed the director of pharmacy services position in the primary training site (KSU Medical City Hospital), the completion of construction of a new pharmacy school building for female students and faculty, and the development of the APPE program supported by key collaborations with hospitals and training sites throughout the region. Prior to the certification visit, KSU-COP administrators organized a roundtable discussion with university and non-university participants to amend or incorporate new recommendations into the APPE curriculum. This article discusses the results from the event and provides insight for current and future ACPE International Certification candidates.

\section{METHODS}

The setting for this discussion was the annual KSUCOP preceptors retreat held on January 1, 2013. Forty-eight participants composed of pharmacists, clinical pharmacists and pharmacy stakeholders from academic hospitals (6), general (30), and private (5) hospitals, regulatory authority (1), primary care (4) and community (2) hospitals were divided into six tables according to the type of rotations and training they offer. The roundtable discussion revolved around three predefined themes: discussion of the PharmD program learning outcomes; regulations and responsibilities; and APPE activities and syllabi, non-clinical rotations, and assessment.

The third theme was the core of the roundtable discussion. It was directly related to the APPE rotations; therefore, the discussion regarding this theme was more comprehensive than the other themes. The primary objective was to solicit recommendations and feedback related to the APPE program; however, this information would be 


\section{American Journal of Pharmaceutical Education 2019; 83 (2) Article 6528.}

incomplete without incorporating a thorough discussion regarding the learning objectives, regulations and responsibilities.

An agenda was provided to each table with specific items to be discussed according to the table theme. The experiential training committee developed these agenda. At the time of the retreat, the experiential training committee consisted of six pharmacists from the clinical pharmacy department selected by the dean of the pharmacy college. They are responsible for organizing and facilitating Introductory Pharmacy Practice Experiences (IPPE) and APPE and typically meet monthly. The roundtable discussions were arranged in collaboration with the pharmacy college administration. They were coordinated as part of the college's self-assessment preparation prior to the ACPE site visit to solicit feedback from stakeholders. The participants were clinical and/or administrative IPPE and APPE preceptors who actively participated in training KSU-COP students. They were divided into three groups based upon their field of expertise and/or experience with the themes to be discussed. A member of the experiential training committee was designated for each table to facilitate and document the discussion.

Table 1 discussion focused on the PharmD program learning outcomes. The curriculum committee originally developed these learning outcomes. It was drafted and revised several times in accordance with the ACPE recommendations and the American Association of Colleges of Pharmacy Center for the Advancement of Pharmacy Education (CAPE) outcomes, and eventually approved by this college. Before the final approval, feedback from the deans and directors of pharmacy was sought at this table regarding these outcomes.

Table 2 focused on regulations and responsibilities specific to the rotation and student conduct. Preceptors were asked to discuss and review the current policies for both IPPE and APPE. They were provided with the rotation manuals and asked to give their feedback regarding attendance, leave of absence policies, student absenteeism, dress code, student financial compensation, conflict resolution, preventive health requirements for students, patient confidentiality, professional conduct, and their recommendations considering the commute between placement sites and this college.

The college's responsibilities and the practice sites were also discussed. Preceptors commented on the preceptor responsibilities listed in the manual, and the role of the college in experiential training. They were asked to discuss student responsibilities and expectations outlined in the manuals and the minimum acceptable amount of time to spend with each student daily/weekly for IPPE and APPE. Although the minimum acceptable amount of time that preceptors must spend with each student has not been standardized in the US, a national survey conducted by Skrabal and colleagues provided some insight into the typical interactions between preceptors and trainees. ${ }^{16}$ Out of 1,085 respondents, $36 \%$ spent $11-20$ hours, $26 \%$ spent $0-10$ hours, $19 \%$ spent $21-30$ hours, $17 \%$ spent 31 40 hours, and $2 \%$ spent over 40 hours per week with APPE students.

APPE activities and syllabi, non-clinical rotations, and assessment were discussed at table 3. Initially, preceptors were asked for suggestions on how KSU-COP can increase the quality and quantity of preceptors and how KSU-COP should give feedback/coaching to individual preceptors to improve their precepting skills. Preceptors were asked to recommend the essential elements of orientation and if there were any suggested preparatory materials and/or activities that should be required for clinical and non-clinical rotations. In addition, they discussed the minimum time for students in direct patient care activities and the type of activities that students may perform independently.

In addition, preceptors were asked to provide their recommendations on the core/minimum responsibilities for students on a patient-care rotation, and the core therapeutic topics that should be covered during clinical rotations. Furthermore, they discussed how to optimize the student experience by integrating them in the practice in a way that will extend patient care.

Regarding the non-clinical rotations, the student evaluation forms were given to the preceptors for their feedback and modifications that would make them more specific and applicable for non-clinical rotations. In addition, they were asked to recommend core non-clinical rotations such as drug information, evidence-based practice, administration, medication safety, research, and informatics.

The discussion was transcribed verbatim. Recommendations and opinions of participants regarding each theme were summarized and incorporated in the results. Confidentiality and anonymity were guaranteed, and all participants were informed that no data that may lead to the identification of any participant would be published in any form.

\section{RESULTS}

Participants at the first table recommended that research methodology, critical thinking, and leadership skills should be added to the program outcomes. In addition, some modifications to the current program outcomes were suggested. It was proposed that the communication skills outcomes be integrated into the leadership ability concept and courses that have common outcomes should be merged. They also suggested that the program should expose students to essential standards of practice (ie, USP 


\section{American Journal of Pharmaceutical Education 2019; 83 (2) Article 6528.}

General Chapter 797 Pharmaceutical Compounding - Sterile Preparations). ${ }^{17}$ They also recommended deleting some of the program outcomes. Emphasis was placed on the basic sciences, especially pharmaceutics. They stressed the importance of pharmaceutics for students in their potential hospital positions in terms of intravenous preparations and product stability. They recommended that students not focus on the other associated basic sciences.

Participants at the second table discussed regulations and responsibilities. Preceptors reviewed the APPE manuals and identified important revisions. They agreed that students should train a full working day, follow the institutional attendance policies, compensate for their absences, and adhere to the institutional policies regarding handling conflicts and protecting the confidentiality of the institution. Preceptors commented that institutions should not compensate the students financially. Historically, the Ministry of Education has provided stipends to Saudi nationals through the Higher Education Fund to encourage students to pursue higher education beyond their secondary studies. ${ }^{18}$ Furthermore, they stressed that it is essential that all students receive the essential immunizations for health care providers as a requirement prior to commencing their internship year.

The most thoroughly discussed theme was at table 3, which was APPE activities and syllabi, non-clinical rotations and assessment. Preceptors agreed that efforts should be focused to foster healthy and productive communication among the college, preceptors, and students. They recommended to increase the number of meetings between the college and the preceptors with continuous education (CE) hours and to provide training courses for the preceptors, such as the American College of Clinical Pharmacy (ACCP) preceptorship program and continuous professional development (CPD) programs.

They highlighted the importance of the college maintaining direct supervision and recommended planned and/ or unplanned visits to the sites by the faculty. Further, meetings between site coordinators, students, and faculty should be conducted at least twice during the experience to discuss evaluations and provide any necessary comments to improve student performance. Preceptors also emphasized the importance of getting the students' feedback to improve future experiences.

They recommended increasing the financial reimbursement and improving the payment methods to increase the number of preceptors working in collaboration with the college either by making contracts or by increasing the resources for the KSU-COP. They agreed on the importance of providing officially recognized academic affiliations for the preceptors such as adjunct professors.

Upon discussing the pre-rotation preparation items, preceptors recommended that preparations be initiated one week before the start of the rotations, and that preparations should include reading the training manuals. They emphasized the importance of providing specialized courses or workshops on professionalism and professional communication to enlighten the students before they enter an actual practice setting. They also highlighted the importance of being prepared clinically by reading the core clinical topics and guidelines and the laboratory interpretation and clinical skills handbooks. Student orientation should start on the first day, and students should be provided with a rotation calendar. They should be oriented to the hospital and its accessible resources such as the Drug Information Center and the hospital library, the EMR system, the procedure of ADR reporting, and safety and emergency policies and procedures.

Regarding the time commitments for rotations, all participants agreed that individual preceptor time spent with students after rounds should be at least 1 hour per day, and that $50 \%$ to $70 \%$ of the student's time should be spent on patient-care activities, such as counseling, medication reconciliation, performing patient interviews and discharge counseling, handling ADRs, nursing education, case presentations, and making drug monographs. Students should be actively involved in the health care team. Likewise, they should be integrated into the practice while focusing on improving their skills in applying the most recent guidelines and clinical updates. Preceptors listed the following areas as the core rotation areas: cardiology, infectious diseases, internal medicine, ambulatory care, and oncology.

Regarding the final evaluation and grading for the students, preceptors agreed that it would be helpful to review each student's portfolio on the first day of each rotation. In this manner, the preceptor can evaluate and challenge the students based upon their own personal level and encourage them to improve. It was recommended to continue student grading on a scale of 1-5 ( $1=$ Poor competency: indicating poor performance; $2=$ Low competency: indicating that the student performs at a level below his/her peers; $3=$ Average competency: indicating that the student demonstrates basic competency; $4=$ Expected competency: the student performs at a level consistent with his/her peers; and 5=High competency: signifying a level of competency superior to his/her peers), and the net result for the rotation will be either to pass or fail the student. These evaluations should be submitted electronically through $\mathrm{E}^{*}$ Value (Minneapolis, $\mathrm{MN}$ ) as opposed to manually submitting them to prevent delays in evaluation submissions. In addition, the final report should be communicated by the site coordinator to the students and faculty.

Regarding the non-clinical rotations, there was a difference of opinion. Some preceptors advocated tailoring 


\section{American Journal of Pharmaceutical Education 2019; 83 (2) Article 6528.}

the current evaluation form specifically for the non-clinical rotations. However, other preceptors suggested keeping the current forms and incorporating explicit evaluation points for the non-clinical rotations. It was also suggested to have some core non-clinical rotations such as Drug Information (DI), Health Information System (HIS), and pharmacy administration.

In conclusion, preceptors highlighted the importance of continuing these advisory committees and suggested to share the best practices and challenges. Student involvement in these meetings, especially recent graduates, was also encouraged.

\section{DISCUSSION}

The results of this qualitative study reflect many of the same concerns and issues addressed by program directors of experiential training as reported by Harralson and Danielson and colleagues. ${ }^{19,20}$ Preceptor development, preceptor stipends, assessment, onboarding students, and support/recognition from the administration continue to be common themes for impetus and will continue through the developmental to the experienced stages. Further, many of these same issues were included in the recommendations for the draft standards for Advancing Quality in Pharmacy Education. $^{21}$

The theme at table one was indirectly related to the APPE rotations. Although pharmaceutics is one of the basic sciences, the preceptors tied this indirectly to many of the experiences that students will encounter during their rotations. Advanced hospital rotations, introductory institutional rotations, DI rotations, and some clinical rotations will likely expose students to situations where their knowledge of pharmaceutics will be beneficial.

Theme two focused on the rules and regulations regarding pharmacy students and their APPE experiences. This included issues primarily related to professionalism and professional responsibilities. Because the discussion focused on table three, the topics discussed at tables one and two supported topic three; however, the discussion regarding these themes was minimal.

Communication was a major issue addressed by the preceptors at table three. They suggested more gatherings between the college administration and faculty and the preceptors. One proposal regarding engagement was on $\mathrm{CPD}$, including clinical knowledge and preceptor skills enhancement. This is similar to the findings of Vos and Trewet who conveyed that preceptors prefer a variety of educational deliveries and options. ${ }^{22}$ Preceptor development programs were provided live, via the internet, on printed materials, and/or in-person. Module titles included Core Preceptor Development Modules, IPPE Development and Implementation, Mentoring, and Ethics for Preceptors. In many of the web-based modules, preceptors agreed that these activities enhanced their values, attitudes, knowledge, skills, and would ultimately improve their practice. Furthermore, Assemi and colleagues identified that preceptor training boosted the confidence of preceptors in their interactions with trainees. ${ }^{23}$

Another issue addressed at this table was a call for more direct supervision and participation from the faculty via announced and unannounced site visits. In reality, this could be categorized as another way of indirectly establishing and maintaining communication between the college and the practice sites. According to Wilber and colleagues, faculty visits to experiential training sites enhanced student perception of the development of their patient care skills. In addition, preceptors acknowledged that these visits were essential to the enrichment of their mentorship skills. ${ }^{24}$ These faculty visits have included observations of formal therapeutic discussions, student patient case presentations, attendance at bedside rounds, attendance at student presentations, and facilitation of communication between the preceptor and the student. Burgett and colleagues also solicited preceptor views regarding faculty site visits. ${ }^{25}$ Approximately $89 \%$ of respondents believed that these visits improved communication between the preceptor and the college, and $76.2 \%$ believed that the visits should continue. In addition to being an asset to their own personal practice and skills, $79.5 \%$ believed that the visits are valuable to the students' development.

Compensation in the form of monetary stipends, access to resources (ie, electronic, library, software, etc.), and faculty appointment continue to be an unaddressed need for many preceptors. These preferred means of compensation were echoed from a previous survey of volunteer pharmacy preceptors by Skrabal and colleagues. ${ }^{16}$ In addition, these are directly and indirectly related to many of the concerns and recommendations for the Accreditation Standards for Doctor of Pharmacy Education in terms of resources, expectations, and responsibility. ${ }^{21}$

Regarding student preparation, preceptors suggested several pre-rotation activities to prepare students prior to beginning their first rotations. Medina and colleagues described a pre-rotation workshop in which students engaged in activities related to patient charts, medication histories, SOAP notes, patient presentations, and professionalism. The students were evaluated using pre- and post-workshop objective structured clinical examinations (OSCE), and participants scored significantly higher after the workshop. However, at the end of the clinical rotations and when compared to the APPE rotation final evaluations of non-workshop participants, there was no difference between the workshop attendees and the nonattendees. However, the sample size was low and this 


\section{American Journal of Pharmaceutical Education 2019; 83 (2) Article 6528.}

study suffered from many limitations. ${ }^{26}$ Furthermore, McLaughlin and colleagues confirmed the weak association between OSCE scores and APPE performance. ${ }^{27}$

Although no direct association between actual student performance and evaluations has been reported, both standardized patient assessment programs and capstone courses have been used to prepare students for APPE rotations with the majority of students successfully completing the programs and courses, respectively. ${ }^{28-30} \mathrm{Re}-$ gardless, basic orientation sessions provided to students are an essential component of each rotation and responsibility has been directed toward the preceptors. ${ }^{4}$

Structure during rotations, a variety of rotation activities, interprofessional interactions, and core rotations, student evaluations, and non-clinical rotation evaluations were all addressed in the discussion. Interestingly, the majority of these topics were specifically addressed in both the Recommendations for the Accreditation Standards as well as the latest ACPE Accreditation Standards. ${ }^{4,21}$ Implementation of the previous standards has been correlated with positive clinical behaviors in students prior to the start of their APPE rotations. ${ }^{31}$

This study has several limitations. There may have been some conflict of interest because some of the preceptors/participants may have been faculty members at other competing pharmacy colleges eager to have their programs certified. Secondly, the discussions were documented manually instead of audio recorded. Many of the responses were summarized and specific pertinent quotes were thus omitted. Thirdly, participation was limited to the attendees, and furthermore, some stakeholders might not have contributed to the discussion because of the number of participants included at each discussion table. Lastly, the discussion was restricted to only one session, and hence one-on-one discussion was not possible.

Future evaluation meetings should include all key stakeholders including pharmacy college administration officials, academicians, clinical faculty, pharmacy hospital administration officials, clinical pharmacists, community pharmacy administration, and industry pharmacy administration. The stakeholders should be assigned to tables/discussions according to their expertise and specialties and all discussion should be recorded and eventually transcribed. A Threats, Opportunities, Weaknesses and Strengths (TOWS) analysis should be performed to evaluate the external environment and a Strengths, Weaknesses, Opportunities and Threats (SWOT) analysis to evaluate the internal environment.

\section{CONCLUSION}

This study highlighted the importance of soliciting the comments and recommendations of essential stakeholders in the preparation for accreditation and/or certification visit interviews. International certification candidates can benefit from discussions such as these as well as the current Accreditation Standards when applying for these types of credentials. This group discussion identified many of the concerns and recommendations previously encountered or currently addressed in many of the previous studies and current Accreditation Standards. International candidates should consider these recommendations when applying for certification.

\section{REFERENCES}

1. Accreditation Council for Pharmacy Education. Accreditation Council for Pharmacy Education mission statement. https://www. acpe-accredit.org/about/. Accessed January 26, 2016.

2. Accreditation Council for Pharmacy Education. International services program. https://www.acpe-accredit.org/internationalservices-program/. Accessed January 26, 2016.

3. Accreditation Council for Pharmacy Education. International quality criteria for certification of professional degree programs in pharmacy. https://www.acpe-accredit.org/pdf/ISP/QualityCriteria. pdf.Accessed January 26, 2016.

4. Accreditation Council for Pharmacy Education. Accreditation standards and guidelines for the professional program in pharmacy leading to the doctor of pharmacy degree. Standards 2016. https:// www.acpe-accredit.org/pdf/Standards2016FINAL.pdf.Accessed January 24, 2016.

5. Accreditation Council for Pharmacy Education. ACPE grants first international program certification 2013. https://www.acpe-accredit. org/pdf/InternationalCertificationPressRelease0711_FINAL.pdf. Accessed January 25, 2016.

6. Accreditation Council for Pharmacy Education. ACPE directory of programs with certification status. 2016. https://www.acpe-accredit. org/pdf/DirectoryCertifiedPrograms.pdf.Accessed May 1, 2016. 7. Asiri YA. Emerging frontiers of pharmacy education in Saudi Arabia: the metamorphosis in the last fifty years. Saudi Pharm J. 2011;19(1):1-8.

8. Al-Sowaygh IA, El-Sayed ME, Abdullah ME. Designing a new curriculum for undergraduate pharmacy in Saudi Arabia. Am J Pharm Educ. 1977;41(1):38-44.

9. Kheir N, Zaidan M, Younes H, El Hajj M, Wilbur K, Jewesson PJ. Pharmacy education and practice in 13 Middle Eastern countries. Am J Pharm Educ. 2008;72(6):Article 133.

10. Saudi Commision for Health Specialties. Guideline of Professional Classification and Registration for Health Practitioners. $6^{\text {th }}$ ed. Riyadh, Saudi Arabia: Saudi Commision for Health Specialties; 2014.

11. Moustafa MAA. Looking for accreditation of pharmacy programs, is it luxury or necessity? J Pharma Care Health Sys. 2015;2:e136.

12. Ibrahim MIM. Clinical pharmacy education in the Middle East and Asia: are we doing it right? J Pharm Pract Res. 2011;41(3):176-178. 13. Aljadhey $\mathrm{H}$. Challenges facing advanced pharmacy practice experience in Saudi Arabia. Am J Pharm Educ. 2013;77(1):Article 19. 14. Asiri YA. Emerging frontiers of pharmacy education in Saudi Arabia: the metamorphosis in the last fifty years. Saudi Pharm J. 2011;19(1):1-8.

15. Canadian Council For Accreditation of Pharmacy Programs. Annual report and directory of accredited programs 2011-2012. Toronto, ON2012. 


\section{American Journal of Pharmaceutical Education 2019; 83 (2) Article 6528.}

16. Skrabal MZ, Jones RM, Nemire RE, et al. National survey of volunteer pharmacy preceptors. Am J Pharm Educ. 2008;72(5): Article 112.

17. Pharmaceutical compounding - sterile preparations (general chapter 797). In: Second Supplement of USP 31-NF 26 and the second edition of the Pharmacists' Pharmacopeia. Rockville, MD: United States Pharmacopeia Convention, Inc.; 2008:3700-3734. 18. Ministry of Education. The Higher Education Fund. 2017; https://www.moe.gov.sa/en/TheMinistry/AboutMinistry/Institutions/ Pages/TheHigherEducationFund.aspx.Accessed October 12, 2017. 19. Harralson AF. Financial, personnel, and curricular challenges of advanced practice experience programs. Am J Pharm Educ. 2003; 67(1):Article 17.

20. Danielson J, Craddick K, Eccles D, Kwasnik A, O'Sullivan TA. A qualitative analysis of common concerns about challenges facing pharmacy experiential education programs. Am J Pharm Educ. 2015;79(1):Article 6.

21. Zellmer WA, Beardsley RS, Vlasses PH. Recommendations for the next generation of accreditation standards for doctor of pharmacy education. Am J Pharm Educ. 2013;77(3):Article 45.

22. Vos SS, Trewet CB. A comprehensive approach to preceptor development. Am J Pharm Educ. 2012;76(3):Article 47.

23. Assemi M, Corelli RL, Ambrose PJ. Development needs of volunteer pharmacy practice preceptors. Am J Pharm Educ. 2011; 75(1):Article 10.

24. Wilbur K, Paiva M, Black E. Pharmacy student and preceptor impressions of faculty liaison visits to experiential training sites. $A m J$ Pharm Educ. 2015;79(9):Article 134.
25. Burgett NE, Dennis VC, Wideman SD, Kirkpatrick AE, Randall DL. Pharmacy preceptors' views on the value and optimal frequency of quality assurance visits to advanced pharmacy practice experience sites. Am J Pharm Educ. 2012; 76(3):Article 48.

26. Medina MS, Stark JE, Vesta KS, Lockhart SM. Evaluating the impact of a pre-rotation workshop on student preparation for clinical advanced pharmacy practice experiences. Pharmacy Pract. 2008; 6(4):219-223.

27. McLaughlin JE, Khanova J, Scolaro K, Rodgers PT, Cox WC. Limited predictive utility of admissions scores and objective structured clinical examinations for APPE performance. Am J Pharm Educ. 2015;79(6):Article 84.

28. Ragan RE, Virtue DW, Chi SJ. An assessment program using standardized clients to determine student readiness for clinical practice. Am J Pharm Educ. 2013;77(1):Article 14.

29. Hirsch AC, Parihar HS. A capstone course with a comprehensive and integrated review of the pharmacy curriculum and student assessment as a preparation for advanced

pharmacy practice experiences. Am J Pharm Educ. 2014;78(10): Article 192.

30. Beatty SJ, Kelley KA, Ha J, Matsunami M. Measuring preadvanced practice experience outcomes as part of a PharmD capstone experience. Am J Pharm Educ. 2014;78(8):Article 152.

31. Mort JR, Laible BR, Johnson TJ. Implementing standards 2007 to improve students' preparation for advanced pharmacy practice experiences. Am J Pharm Educ. 2011;75(4):Article 74. 